\title{
Atuação de tradutoras e intérpretes de Língua Brasileira de Sinais no ensino não presencial
}

\section{Performance of translators and interpreters of Brazilian Sign Language in non-face to face teaching}

\author{
Janete Inês Müller ${ }^{1}$ \\ Mirele Pretto da Silva²
}

\begin{abstract}
Resumo
Este artigo analisa o trabalho desempenhado por Tradutores e Intérpretes de Língua Brasileira de Sinais (TILS) em tempos de ensino não presencial, decorrente da pandemia do Covid-19 no Brasil. Para isso, os referenciais teóricos utilizados consideram a legislação brasileira e estudos sobre tradução e interpretação, situados no campo da Linguística e da Educação. Com o objetivo de investigar o trabalho dos TILS, foram desenvolvidas entrevistas virtuais com profissionais que atuam em um Instituto Federal do estado do Rio Grande do Sul, observando o trabalho desenvolvido, as estratégias utilizadas e as adaptações necessárias para a produção de material virtual e acessível em Libras. Desse modo, são viabilizados processos educacionais inclusivos, sobretudo para a garantia de acessibilidade aos surdos vinculados à Instituição: estudantes, servidores e comunidade em geral. Conclui-se que, em atuações não presenciais, os TILS: realizam investimentos para deslocamento de suas atividades em seus ambientes familiares, buscando avançar na qualidade das produções caseiras; trocam experiências com colegas de profissão, qualificando seu trabalho por meio aprendizagens compartilhadas; têm demanda significativa de tradução e interpretação, para a garantia da acessibilidade linguística aos surdos; qualificam suas práticas por meio do trabalho em rede; e, em meio a um processo de potencialidades e fragilidades, vêm criando e fortalecendo laços com a comunidade surda.
\end{abstract}

Palavras-chave: Tradutor e Intérprete de Libras. Ensino não presencial. Inclusão.

\begin{abstract}
This article analyzes the work performed by Brazilian Sign Language Translators and Interpreters (TILS) in times of nonpresential teaching, resulting from the Covid-19 pandemic in Brazil. For this, the theoretical references used consider Brazilian legislation and studies on translation and interpretation, located in the field of Linguistics and Education. In order to discuss the work of TILS, virtual interviews were developed with professionals who work at a Federal Institute in Rio Grande do Sul, observing the work developed, the strategies used and the necessary adaptations for the production of virtual material. In this way, inclusive educational processes are made possible, especially to guarantee accessibility to the deaf linked to the Institution: students, servers and the community in general. It is concluded that, in non-face-to-face activities, TILS: make investments to move their activities to family environments, seeking to advance the quality of home productions; exchange experiences with professional colleagues, qualifying their work through shared learning; they have a significant demand for translation and interpretation, to guarantee linguistic accessibility to the deaf; qualify their practices through networking; and, in the midst of a process of strengths and weaknesses, they have been creating and strengthening ties with the deaf community.
\end{abstract}

Keywords: Libras translator and interpreter. Non-face to face teaching. Inclusion.

\footnotetext{
${ }^{1}$ Doutora em Educação. Instituto Federal de Educação, Ciência e Tecnologia Sul-rio-grandense, Venâncio Aires, Rio Grande do Sul, Brasil. Orcid: https://orcid.org/0000-0002-5352-7127. E-mail: janetemuller@ifsul.edu.br.

${ }^{2}$ Especialista: Pesquisa em Educação. Instituto Federal de Educação, Ciência e Tecnologia do Rio Grande do Sul, Caxias do Sul, Rio Grande do Sul, Brasil. Orcid: https://orcid.org/0000-0002-1861-927X.E-mail: mirelepretto@gmail.com.
} 


\section{Introdução}

Desde o mês de março do ano de dois mil e vinte (2020), a sociedade brasileira vive um momento muito delicado, de modo a conviver com o Coronavírus (COVID-19). O estado pandêmico, em âmbito mundial, mobilizou a população a ficar em isolamento social, o que foi necessário para contenção do avanço de um vírus mortal. Desse modo, mudanças foram precisas, inclusive na Educação, de modo que estudantes e acadêmicos surdos, isolados em suas residências, pudessem se comunicar e ter acesso à formação escolar em Libras - Língua Brasileira de Sinais.

Nos termos da lei, foram necessárias estratégias para sanar as demandas de acessibilidade existentes em plataformas de ensino, de modo a garantir o ensino na modalidade EaD e remoto. Nesse contexto, os estudantes surdos foram inseridos no ambiente virtual de aprendizagem, podendo usufruir dessa ferramenta. $O$ acesso à informação é relevante e necessário ao sujeito surdo, de modo a lhe oportunizar conhecimento acessível, neste caso em Libras, o que é garantido na legislação brasileira e faz parte dos objetivos das Instituições de Ensino. A partir disso, o trabalho de tradução e interpretação passou a ser pensado e praticado de maneira diferente do comumente presencial. Assim, os intérpretes necessitaram se (re)adaptar à realidade, buscando reinventar a sua atuação para a promoção da informação aos surdos em um ambiente virtual.

A fim de problematizar essa realidade, nesta investigação, objetiva-se verificar as principais alterações nos ambientes de trabalho dos Tradutores e Intérpretes de Língua Brasileira de Sinais (TILS) e suas estratégias para permanecerem trabalhando de forma remota em um cenário pandêmico. Mais especificamente, investigam-se os caminhos encontrados pelos tradutores e intérpretes de Libras, percebendo as adaptações feitas para a prática tradutória em um espaço domiciliar e as demandas existentes para a interpretação acontecer em ambiente virtual de ensino, garantindo a inclusão e acessibilidade. Em meio a um processo de potencialidades e fragilidades, em tempos de ensino não presencial, cabe problematizar de que modos os TILS vêm criando e fortalecendo laços com o público surdo.

Nessa esteira de pensamento, este artigo, a partir da próxima seção, compreende discussões teóricas sobre os processos de tradução e interpretação. Ao se analisar as práticas desenvolvidas por tradutores e intérpretes de Libras/Língua Portuguesa em período de pandemia, este artigo é desenvolvido com referenciais teóricos que consideram a legislação brasileira, bem como estão articulados ao campo da Linguística e da Educação. Na sequência, apresentam-se os caminhos metodológicos e são analisadas as entrevistas virtuais realizadas com TILS que atuam em um Instituto Federal do estado do Rio Grande do Sul. E, nesse caso, discute-se o papel ético e social desempenhado 
pelas TILS, suas demandas e avanços profissionais, as estratégias utilizadas e as adaptações para a produção de material a ser inserido no ambiente virtual, de modo que sejam favorecidos os processos educacionais inclusivos.

\section{Tradução e interpretação Libras/Português na inclusão de estudantes surdos}

\subsection{Processos de tradução e interpretação}

É possível afirmar que o processo tradutório se dá a partir do momento em que duas culturas com línguas distintas se deparam, constituindo-se o cerne de uma tradução. $O$ ato de traduzir é constituído de inúmeros detalhes, engloba características específicas, exigindo habilidades e competências para transmitir e significar as informações. Também conhecer e se apropriar de diferentes modalidades de linguagem, como os gêneros textuais e as características culturais de determinado país, é pertinente para que seja possível realizar um trabalho coeso e sem equívocos nas perspectivas tradutórias. Campos (1986) contribui com conceito básico de tradução, como se lê no trecho a seguir:

\footnotetext{
O verbo "traduzir" vem do verbo latino traducere, que significa "conduzir ou fazer passar de um lado para o outro", algo como "atravessar". [...] A língua em que um texto a traduzir é originalmente escrito pode ter os nomes de língua-fonte ou língua de origem ou língua de partida [...]. A língua para a qual se faz passar um texto originalmente escrito em outra pode chamar se língua-meta ou língua-alvo ou língua-termo ou língua de chegada. (CAMPOS, 1986, p. 7-8).
}

Traduzir para uma língua-alvo compreende uma bagagem repleta de saberes e conhecimentos, com respeito à mensagem a ser traduzida por intérpretes éticos e fidedignos no âmbito profissional. Masutti e Santos (2008, p. 152) mostram que os processos tradutórios estão repletos de marcas inconscientes, pois cada intérprete pode realizar a marcação simbólica que mais Ihe traz afinidade. Ainda, no campo da tradução, segundo Bassnet, com base em Jakobson, (2005, p. 36), há três formas de realizá-la: tradução intralingual, quando temos uma interpretação dentro de uma mesma língua, porém com signos readaptados e com a utilização necessária de sinônimos; tradução interlingual, quando há o câmbio entre duas línguas distintas; e tradução intersemiótica, em que se utiliza uma interpretação com signos não-verbais. No caso da tradução Libras/Português, há um processo de tradução que compreende uma língua oral (português) e uma de modalidade viso-gestual (língua de sinais).

Embora já utilizada há mais tempo, a Libras foi legalmente reconhecida a partir de 24 de abril de 2002, com base na Lei Federal $n^{0}$ 10.436, compreende-se "como Libras a forma de comunicação e expressão, em que o sistema linguístico de natureza visual - motora, com estrutura gramatical própria, 
constitui um sistema linguístico de transmissão de ideias e fatos, oriundos de comunidades de pessoas surdas do Brasil" (BRASIL, 2002). É importante compreender a língua de sinais como uma condição fundamental para a inserção social e o reconhecimento da pessoa surda, sendo esta capaz de perceber sua força para interagir e participar de forma atuante na sociedade em que vive. A utilização da língua de sinais propicia uma série de avanços sociais e psicológicos, uma vez que o sujeito surdo tem a língua como forma de expressão, de escolhas e de exercício da cidadania. Caminhando nessa direção, compreende-se que a inclusão escolar não pode se dar apenas na forma física; seu foco é, claramente, a inclusão na aprendizagem, na aquisição do conhecimento, o que, no caso dos estudantes surdos, acontece em língua de sinais.

A presença física como justaposição não garante que os aprendizes estejam integrados uns com os outros, aprendendo e participando de todas as atividades escolares. Além da inserção física, é indispensável que todos os estudantes sejam beneficiados com a inclusão na aprendizagem e com a inclusão social, exercitando e desenvolvendo a plena cidadania (CARVALHO, 2005, p. 2).

No processo inclusivo, é necessário dar suporte, para que o estudante surdo consiga se apropriar do conhecimento científico. Partindo da realidade escolar e da construção do processo inclusivo no ambiente de ensino, historicamente, foi possível avançar na compreensão do atual conceito de inclusão. O termo incluir mostra a ação de inserir o aluno com deficiência no ambiente escolar, proporcionando a ele recursos e estratégias específicas para uma melhor compreensão do conteúdo, respeitando suas limitações e proporcionando bem-estar e conhecimento.

A Declaração de Salamanca (1994) representa um avanço ao entender que a escola é "para todos", evidenciando que as diferenças devem ser reconhecidas e que a necessidade de cada indivíduo deve ser respeitada; a partir dela, espera-se a promoção da aprendizagem. Neste contexto de "escola para todos", o sujeito surdo passa a fazer parte do processo inclusivo. Embora apenas a mediação do/a profissional tradutor/intérprete de Libras não seja suficiente nos processos inclusivos, é por meio de sua atuação que é garantida a acessibilidade linguística aos estudantes surdos. 0 papel desse profissional é discutido na sequência deste texto, sobretudo na articulação ao trabalho em um Instituto Federal situado no estado do Rio Grande do Sul.

\subsection{Tradutores e Intérpretes de Língua Brasileira de Sinais e suas atribuições}

Um tradutor e intérprete de Libras pode ser considerado um interlocutor da informação, que repassa, de forma íntegra, ética e com o mínimo de ruídos linguísticos, um conteúdo específico de uma 
língua oral (língua falada) para outra visuo-espacial (línguas de sinais), e vice-versa. Assim, por meio desse profissional, a pessoa surda tem o acesso à informação e ao conhecimento. Esse profissional é um dos principais responsáveis pela efetiva inclusão, com papéis que transcendem a interpretação de aulas, palestras e reuniões. As ações realizadas pelos Institutos, bem como o suporte nas resoluções de atividades não presenciais chegam ao estudante surdo através dos TILS.

$\mathrm{Na}$ perspectiva da educação inclusiva, o tradutor e intérprete é protagonista do processo educacional. $O$ ingresso desse profissional no quadro de funcionários do Instituto aqui investigado se dá de três formas: concurso público, seleção através de provas práticas e de títulos para assumir a vaga como contrato temporário (tempo máximo de dois anos) e através da contratação no modo terceirizado. Partindo disso, os TILS atuam de forma fiel e profissional dentro do ambiente de ensino-aprendizagem. $\mathrm{O}$ sujeito surdo necessita dessa acessibilidade linguística para compreender o que vem acontecendo e acompanhar suas responsabilidades dentro do espaço educacional. Também cabe considerar que 0 intérprete é responsável diretamente pelo trabalho que exerce, o que tem implicações em contextos de ensino-aprendizagem que se dão em Língua Portuguesa e Libras.

Informar, esclarecer, conversar, interpretar palestras e reuniões, esclarecer dúvidas sobre processos internos e auxílios, entre outras atividades são modos de promover vínculos entre TILS e sujeitos surdos (estudantes, professores surdos). A interpretação realizada em contextos educacionais visa proporcionar um canal de aprendizagem digna, respeitoso linguisticamente, de aperfeiçoamento profissional aos surdos, já que ali buscam-se informações e aprendizado; para tanto, o acesso linguístico, sobretudo em cursos técnicos e profissionalizantes, é de suma importância. Em geral, o trabalho desses profissionais é regido pelo Código de Ética vigente, que aborda sua forma de atuação, como pode ser lido a seguir:

\begin{abstract}
A sua existência justifica-se a partir do tipo de relação que o intérprete estabelece com as partes envolvidas na interação. $O$ intérprete está para intermediar um processo interativo que envolve determinadas intenções conversacionais e discursivas. Nestas interações, o intérprete tem a responsabilidade pela veracidade e fidelidade das informações. Assim, a ética deve estar na essência desse profissional (BRASIL, 2004, p. 31).
\end{abstract}

No contexto atual de pandemia, ressignifica-se a atuação do tradutor e intérprete de Libras, modificando os modos de percepção, comunicação e interação no mundo. É com o profissionalismo dos TILS que as informações referentes à pandemia do Covid-19 e as ações realizadas pelas Instituições também chegam aos estudantes e servidores surdos. $O$ foco de atuação, portanto, é viabilizar condições para acesso ao material disponível, de forma gratuita, em sua plataforma de ensino. Para isso, TILS têm buscado adaptar e tornar acessiveis alguns materiais, de modo que estes, inseridos em um ambiente 
virtual, garantam aos surdos a interação com o canal institucional e as informações por ele veiculadas. Por isso, na sequência deste texto, problematizam-se estratégias e ferramentas necessárias para 0 desenvolvimento do trabalho tradutório, sobretudo de modo não presencial.

Com base nisso, defende-se que a inclusão de surdos é possível, principalmente a partir do momento em que se tem intenção, empenho, investimento, empatia, conhecimento, confiança e respeito pelo processo educacional em que estamos inseridos. Proporcionar um espaço adequado de aprendizagem e de vivências escolares é dever do Estado e direito de todo o cidadão brasileiro. Uma escola inclusiva é construída com professores, administração, estudantes com e sem necessidades especiais, abertos ao contato e dispostos a aprenderem com o processo inclusivo. Na relação com a pesquisa, é possível problematizar e mudar realidades nas instituições educacionais.

\section{Caminhos de pesquisa e os dados produzidos}

Os Institutos Federais têm avançado em suas ofertas de ensino na busca pela permanência e êxito dos estudantes e na promoção da inclusão de pessoas com deficiência. Com isso, percebe-se maior demanda na contratação de tradutores e intérpretes de Libras, uma vez que são fundamentais no acesso e no êxito acadêmico dos estudantes surdos na Instituição. Cabe acrescentar que todo sujeito surdo tem o direito à acessibilidade linguística garantida pela Lei 10.436, de 24 de abril de 2002, com ensino em Libras ou mediado por TILS.

Observa-se, entretanto, que a maioria das informações veiculadas de forma on-line não possui acessibilidade comunicativa que possibilita compreensão às pessoas surdas, fazendo com que não absorvam a informação de forma íntegra e satisfatória. A falta de materiais acessíveis acarreta incompreensão de assuntos (conhecimento de mundo), falha no processo comunicativo e prejuízos no processo de aprendizagem. Pensando nisso, intérpretes efetivos, contratados e terceirizados de um Instituto Federal uniram esforços para suprir as demandas de interpretação pertinentes ao atual momento de isolamento social.

Com o objetivo de problematizar o trabalho dos TILS em tempos de pandemia no país, foram desenvolvidas entrevistas virtuais com seis (06) TILS, que atuam em diferentes Campus de um Instituto Federal do Rio Grande do Sul (RS). Nesse caso, analisou-se o trabalho desempenhado, as estratégias utilizadas e as adaptações necessárias para a produção de material a ser inserido em um ambiente virtual. Desse modo, por meio dessa problematização, a discussão sobre os processos educacionais inclusivos, principalmente a garantia de acessibilidade e da comunicação entre estudantes e servidores, 
entre surdos e ouvintes são pertinentes para compreender os movimentos realizados por esses profissionais.

As tradutoras e intérpretes de Libras participantes desta pesquisa são nomeadas a cargos públicos, com formação específica na área de atuação. Nesta investigação, garante-se e preserva-se a identidade das participantes da pesquisa e, por isso, na sequência deste texto, serão identificadas com nomes fictícios, observando-se itens do Termos de Consentimento Livre e Esclarecido (TCLE) e questões éticas em contextos de pesquisa. Quanto ao gênero das participantes, vale ressaltar que, historicamente, segundo Vianna (2002), a prevalência de mulheres na área educacional acontece há muito tempo, quando elas começaram a atuar como professoras do nível primário, permanecendo até hoje essa característica de gênero no campo da Educação, inclusive estendendo-se para a tradução e interpretação em Libras/Língua Portuguesa. Em alguns casos, os intérpretes são filhos de pais surdos, tendo contato com a língua de sinais desde cedo.

No processo de produção de dados, foram realizadas entrevistas virtuais, por meio do Google Meet, compreendendo perguntas sobre a prática profissional atual, a estrutura necessária para tal ação, as demandas existentes e as estratégias adotadas, além de aprendizagens decorrentes da prática da tradução e da interpretação em tempos de pandemia no país. As entrevistas on-line caracterizam-se como potente estratégia metodológica, porque possibilitam acessar várias pessoas e em diferentes lugares e tempos, facilitando aproximações entre o entrevistador e entrevistados que possam estar distantes geograficamente. A partir da análise discursiva dos resultados, foi possível organizar três importantes pontos de discussão, que são abordados na sequência deste artigo: adaptações e mudanças no trabalho dos TILS, as demandas em tempos de educação não presencial e os avanços neste processo.

\subsection{Mudanças e adaptações no trabalho dos TILS}

O deslocamento de atividades presenciais para um contexto remoto e virtual indicou a necessidade de tornar acessíveis os muitos cursos disponíveis na plataforma digital da Instituição, a qual também disponibiliza conteúdo voltado para a Educação a Distância (EaD). Por isso, interpretar os conteúdos já existentes na plataforma, disponibilizando vídeos em Libras, possibilitou ampliar o acesso de pessoas surdas a esse espaço de formação. Acrescenta-se a isso, a comunicação entre todos os profissionais envolvidos neste processo, que se se deu através de grupos fechados em redes sociais, caracterizando-se como um trabalho colaborativo. 
De forma efetiva, os cursos foram distribuídos entre intérpretes já atuantes nos Campus; por meio de trabalhos em duplas, em contexto não presencial, as traduções e interpretações foram realizadas considerando afinidade com o conteúdo, conhecimento prévio e domínio de vocabulário específico da área escolhida. Em comunicações e reuniões virtuais entre TILS, a organização da demanda existente foi exposta, mostrando o que, de fato, deveria ser interpretado, pensando na necessidade imediata dos estudantes desta rede.

Primeiramente a realização da leitura do material didático dos cursos disponíveis foi disponibilizado, através do acesso à plataforma Moodle. A partir deste momento os intérpretes realizaram os processos tradutórios pertinentes. Posterior à finalização do material em vídeo, com uma primeira edição, o material foi compartilhado em plataforma do Google Drive, para outros profissionais realizarem as devidas avaliações e revisões linguísticas. Desse modo, foi possível tornar os cursos acessíveis ao público surdo, compondo um material que, antes da pandemia, não contava com acessibilidade linguística.

Neste contexto, é importante considerar que o processo de filmagem foi realizado de forma autônoma e individual, exigindo que o intérprete realizasse todo o processo sem auxílio de outras pessoas. Vale ressaltar que as filmagens foram feitas conforme material e ambiente que cada um possuía em sua residência, efetuado de forma caseira e informal. As edições e revisões dos vídeos, para posterior inserção no ambiente virtual, foram realizadas por uma comissão de professores surdos e servidores. Esse trabalho de filmagem, gravação e edição pode ser considerado uma das principais mudanças e adaptações no trabalho dos TILS em contexto de ensino não presencial desta Instituição de Ensino.

Em geral, durante este momento de pandemia, fica evidente que, no Brasil, os intérpretes sofreram alterações em sua prática profissional, desde investimentos feitos na aquisição de equipamentos e técnicas de edição de vídeo, até adaptações em seus ambientes familiares, já que alguns espaços domiciliares passam a ser caracterizados como estúdios. Essas adaptações são necessárias para os TILS continuarem sua atuação profissional, buscando avançar na qualidade das produções caseiras. Nas entrevistas realizadas com as seis (06) participantes desta investigação, é possível observar estas mudanças, considerando-se, principalmente, os ditos que compõem o quadro a seguir:

"Optei por organizar o quarto do meu filho, investi em alguns equipamentos, assim tenho um local mais adaptado para atuar". (Laura)

"Tive que organizar um mini estúdio na minha casa, busquei por me aprimorar em programas de edição e comprei equipamentos de iluminação para realizar meu trabalho". (Sara) 
"Foi necessário adaptar o quarto do meu filho. Transformei em um estúdio de filmagem, ainda bem que tenho apoio do meu campus, no empréstimo de materiais para filmagem". (Karla)

"Investi em materiais para o trabalho remoto, comprei painel, iluminação e adaptei meu quarto para isso". (Jéssica)

"O material que consegui foi todo emprestado, alguns materiais foram disponibilizados pelo IF e outros de amigos, que me emprestaram". (Greice)

Quadro 1. Adaptações técnicas.

Fonte: Autoras (2020).

Esses dados possibilitam concluir que as profissionais necessitaram deslocar o seu local de trabalho para dentro de suas residências. Vale lembrar que nem todas as participantes desta pesquisa conseguiram ou optaram por adquirir materiais para tal prática, uma vez que exige investimento financeiro particular e espaço físico para essa modificação. Adaptações foram improvisadas para suprir as demandas interpretativas, até porque, como dito por elas, em nenhum momento de suas vidas pensaram que teriam que trazer o seu trabalho para dentro de casa. Desafiar-se e reorganizar a prática foram formas de perceber os caminhos que a profissão está tomando em contextos não presenciais.

Pintar uma parede do quarto de casal, transformar o quarto do filho em estúdio, ampliar o pacote de internet, dominar os aplicativos e torcer para que a rede não oscile, entre outros pontos, foram recursos e estratégias importantes, também com compreensão e investimento familiar. Em alguns casos, o estúdio foi uma parede de sua casa, as filmadoras, seus celulares. Vale lembrar que houve baixa oferta de recursos do Instituto, de modo a sanar essas necessidades e produzir material institucional com qualidade.

Com a crescente necessidade de acesso à informação, os intérpretes do Instituto foram desafiados a produzir cada vez mais materiais visuais, necessários também para as aulas regulares em tempos de isolamento físico. As traduções e interpretações, registradas em vídeo, foram realizadas nas acomodações particulares de cada TILS; logo, os materiais audiovisuais de palestras, reuniões, interpretações de documentos, entre outras atividades, não possuíam uma qualidade e formatação padrão. A falta de internet adequada, de softwares e de equipamentos específicos para atuação virtual dos TILS não foram barreiras para realizar o trabalho da melhor forma possível, proporcionando acessibilidade aos estudantes surdos.

Entre os principais desafios, cabe destacar que estar em ambiente familiar faz com que outros afazeres sejam realizados concomitantemente ao seu ofício, o que, segundo as entrevistadas, também acaba influenciando na produção do material. Outro ponto de dificuldade por elas mencionado diz respeito à iluminação do local para a sinalização em Libras. A busca por aplicativos de edição foram 
barreiras enfrentadas e superadas pelos profissionais neste momento de mudanças e de adaptações no trabalho.

\subsection{TILS na educação não presencial: demandas e avanços profissionais}

Assim como em demais profissões, sobretudo no campo da Educação, o trabalho não presencial acabou exigindo uma atuação mais ampla do profissional TILS, suas demandas se ampliaram com velocidade e complexidade, incluindo responsabilidades em reuniões, aulas e lives promovidas pela Instituição. O aumento de eventos virtuais fez com que os intérpretes fossem mais contatados para 0 trabalho. Paralelamente a isso, muitas programações tornaram-se mais acessíveis às pessoas com deficiência, uma prática importante nos processos de inclusão. Assim, alguns TILS tiveram aumento de sua demanda de atuação por também buscarem promover acessibilidade em locais que transcendem seus postos de trabalho. Essas questões são confirmadas pelas participantes desta pesquisa, como se observa no quadro a seguir:

"Tivemos uma ampliação de nossa demanda: lives e gravações de vídeos foram o maior foco". (Laura) "Muitas foram as mudanças e adaptações, aprender a usar a plataforma". "Muitos vídeos e aulas, alunos fazendo muitas disciplinas". (Michele)

"A demanda ampliou muito, documentos, reuniões, palestras, cultural e academicamente tivemos um avanço no nosso trabalho, mediação para a assistência estudantil até auxiliar alunos e pais no auxílio alimentação". (Sara)

"Sinto que ampliamos nossa demanda, uma vez que tivemos que suprir as necessidades da reitoria". "Percebo que pelo apoio à reitoria, acabamos recebendo um olhar diferenciado do público". (Karla)

"Damos visibilidade para a acessibilidade, através de nossa presença em eventos e palestras". (Jéssica)

"Os surdos passaram a nos ver mais, acessibilidade e qualidade seria interessante se mantivéssemos no pós-pandemia". (Greice)

Quadro 2. Demanda atual das TILS.

Fonte: Autoras (2020).

As respostas das entrevistadas também indicam a necessidade de atenderem às necessidades da Reitoria e de Campus que não possuem o profissional tradutor e intérprete no grupo de servidores. Realizar interpretações de reuniões e palestras entre colegas desconhecidos pode ser descrito como uma prática promissora entre TILS da Instituição, de modo que essas interações viabilizaram aprendizagens compartilhadas, o que é importante para o crescimento profissional. Cabe destacar que as participações em ambientes virtuais deram mais visibilidade aos TILS, reconhecendo-se a dedicação a um trabalho que tem sido cada vez mais exigido pelo público. Como disse uma das entrevistadas, 
espera-se que essas mudanças relacionadas à acessibilidade linguística sejam práticas comuns após a pandemia.

Em geral, diante da intensificação das demandas de trabalho dos TILS, consequentemente aumentando a carga horária de trabalho informal, foi necessário observar atentamente o Plano de Lei ${ }^{\circ}$ 9382/2017, que está em tramitação, no qual consta que a carga horária máxima para o profissional TILS é de seis (06) horas diárias ou trinta (30) horas semanais, além de assegurar a atuação em conjunto com outro profissional em caso de trabalho com duração de mais de uma (01) hora. Desta forma, ao limitar a atuação, preza-se pela qualidade do serviço e pelo respeito ao profissional envolvido neste trabalho, já que lhe exige significativo empenho físico e mental, bem como a constante interação social, sobretudo no contato visual com pessoas surdas.

Nesse contexto de ressignificação do trabalho dos TILS no ensino não presencial, é importante destacar o papel exercido pelas tecnologias, que viabilizaram a exitosa prática profissional. Segundo Hamawaki e Pelegrini (2009), a revolução, em especial das tecnologias de comunicação, permite ao aluno obter diferentes meios de pesquisa e interatividade com os professores, outros colegas e com 0 meio que 0 circunda. $E$ isso pode ser possivel em um processo no qual as ferramentas virtuais estão aliadas à atuação dos tradutores e intérpretes de Libras, isto é, a colaboração é fortalecida pelas pessoas e os recursos que elas utilizam para qualificar a prática profissional, como pode ser observado no quadro abaixo.

"A pandemia nos aproximou, conseguimos suprir muitas dúvidas e obtivemos auxílio das colegas via app, o que foi muito bom." [...] "Podemos crescer neste momento, estreitar laços foi fundamental". (Laura)

"Com o início da suspensão das atividades, a interação entre os intérpretes melhorou muito. Hoje mantemos contato, quase que diariamente, através de grupos de whatsapp. Além disso, discutimos sobre nossas práticas de trabalho nos Campis, trocamos informações sobre equipamentos para trabalho remoto e, principalmente, nos apoiamos nas dúvidas sobre sinais". [...] "Nosso trabalho nas reuniões on-line, lives e eventos institucionais nos aproximou enquanto equipe de TILS do IF". (Sara) "Podemos aprender e trocar diferentes sinais, perceber como utilizá-los, isso foi muito importante". [...] "As alterações de práticas de interpretação nas reuniões foram de extrema importância". (Karla) "Vejo muita troca entre os profissionais, nos ajudamos muito". [...] "Ter o grupo é muito bom, pois fazemos muitas trocas, há muito auxílio". (Jéssica)

"Sinto que houve uma solidariedade entre os Campis, uma maior interação, o trabalho em equipe se mostrou presente, senti uma união." [...] "É bom poder ter um retorno de meu trabalho, através dos vídeos realizados, me sinto segura". (Greice)

Quadro 3. Trabalho colaborativo das TILS.

Fonte: Autoras (2020). 
Observa-se também o fortalecimento da categoria, sobretudo devido à aproximação entre os TILS, à troca de saberes e de experiências, ao apoio e à solidariedade obtidos no trabalho em rede. Os dados produzidos nas entrevistas evidenciam a importância dessa prática, que auxilia, une, aproxima, dá segurança, estreita laços, permite evoluções, qualifica os processos de tradução e de interpretação, isso tudo é possível por meio do uso adequado de alguns recursos e aplicativos funcionais em tempos de distância física. Assim, se, por um lado, há aumento da demanda de trabalho, de outro, cabe destacar que algumas mudanças dão condições para a qualificação profissional dos TILS. E que estas venham para fortalecer o trabalho das TILS e serem aprimoradas ao longo dos próximos tempos!

\section{Conversas (quase) finais}

Em meio a um processo de potencialidades e fragilidades, as significativas mudanças na atuação dos TILS também criam e fortalecem laços com as comunidades e os sujeitos surdos. Desse modo, Santos (2020) reforça que o trabalho dos intérpretes e tradutores de Libras/Língua Portuguesa não se resume apenas à inserção de tecnologia e de ferramentas que supram as demandas de tradução e interpretação; mais que um profissional atualizado tecnologicamente e articulado a um professor, é importante o TILS estar conectado ao estudante. E este é um importante papel social desempenhado pelos TILS, sendo uma força nos processos de inclusão escolar.

Tais considerações remetem ao conceito inclusão que, segundo Mantoan (2003), é uma possibilidade que se abre para o aperfeiçoamento da educação escolar e para o benefício de todos os alunos, com e sem deficiência, marcando uma mudança de atitude diante do 'outro'. Nesse sentido, há que se mudar propostas educacionais, adequar métodos e recursos, romper fronteiras entre saberes, aprender mutuamente, estudar de modo contínuo, acompanhar atentamente e intervir nos singulares processos de aprendizagem, promovendo uma cultura institucional sem preconceitos, democrática, competente e que seja de todos, para todos e com todos! Com base nisso, é possível afirmar que as mudanças nos processos de tradução e de interpretação em Libras, decorrentes do ensino não presencial, foram e vêm sendo uma alternativa que subsidia condições para a inclusão de surdos nesta Instituição.

A temática proposta é mobilizadora e pode ser profícua para contemplar reflexões e abordagens diferentes e promissoras para a prática tradutória e de interpretação, considerando as múltiplas realidades surdas em contexto de isolamento social. Através desta pesquisa, evidenciam-se os deslocamentos das atividades profissionais dos TILS para os ambientes familiares; também há 
investimentos financeiros e qualificação do seu trabalho através da cooperação entre profissionais. Enfim, os processos inclusivos compreendem sujeitos, particularidades, práticas, mudanças, desafios e experiências através das quais todos podem aprender, sobretudo na relação com quem é diferente.

\section{Referências}

BASSNET, Suzan. Estudos da tradução. Porto Alegre: Editora da UFRGS, 2005.

BRASIL. Lei n. 10.436, de 24 de abril de 2002. Dispõe sobre a Língua Brasileira de Sinais - LIBRAS - e dá outras providências. Diário Oficial da União, Brasília, DF, 24 abr. 2002. Disponível em: http://www.planalto.gov.br/ccivil_03/leis/2002//10436.htm. Acesso em: 25 mar. 2021.

BRASIL. Secretaria de Educação Especial - Programa Nacional de Apoio à Educação de Surdos. 0 tradutor e intérprete de Língua Brasileira de Sinais e Língua Portuguesa. Brasília: MEC; SEESP, 2004. Disponivel em: https://www.gov.br/mec/pt-br/publicacoes-secretarias/semesp/o-tradutor-e-interprete-delingua-brasileira-de-sinais-e-lingua-portuguesa. Acesso em: 25 mar. 2021.

BRASIL. Projeto de Lei 9382/2017. Dispõe sobre o exercício profissional e condições de trabalho do profissional tradutor, guia-intérprete e intérprete de Libras, revogando a Lei $n^{0} 12.319$, de $1^{\circ}$ de setembro de 2010. Brasília: Câmara dos Deputados, 2017. Disponível em: https://www.camara.leg.br/proposicoesWeb/fichadetramitacao?idProposicao=2166683. Acesso em: 24 mar. 2021.

CAMPOS, Geir. O que é tradução. São Paulo: Editora Brasiliense, 1986.

CARVALHO, Rosita Edler. Educação Inclusiva: do que estamos falando? Revista Educação Especial, n. 25, 2005. Disponível em: https://periodicos.ufsm.br/educacaoespecial/article/view/4395. Acesso em: 22 mar. 2021.

DECLARAÇÃO DE SALAMANCA: sobre princípios, políticas e práticas na área das Necessidades Educativas Especiais. Salamanca, Espanha: 1994.

HAMAWAKI, Marina Hideko; PELEGRINI, Camila de Maria. As ferramentas do ensino a distância e suas contribuições para a eficácia no processo de aprendizagem do aluno. Revista CEPPG, ano XII, n. 21, 2009. http://www.portalcatalao.com/painel_clientes/cesuc/painel/arquivos/upload/temp/b7632647fce4a8a50fd a143156336f90.pdf. Acesso em: 23 mar. 2021.

MANTOAN, Maria T. E. Uma escola de todos, para todos e com todos: o mote da inclusão. In: STOBÄUS, Claus D.; MOSQUERA, Juan J. M. Educação especial: em direção à Educação Inclusiva. Porto Alegre: EDIPUCRS, 2003. 
MASUTTI, Maria Lucia; SANTOS, Silvana Agnir dos. Intérprete de língua de sinais: uma prática em construção - estudos surdos III. In: QUADROS, Ronice Muller de (Org.). Estudos surdos III. Rio de Janeiro: Arara Azul, 2008.

SANTOS, Rayssa Feitoza Felix Dos. A atuação do intérprete de libras em tempos de pandemia: reflexões acerca de possibilidades e desafios. In: IV CONGRESSO INTERNACIONAL DE EDUCAÇÃO INCLUSIVA, 2020. Anais IV CINTEDI. Campina Grande: Realize Editora, 2020. Disponível em: https://editorarealize.com.br/artigo/visualizar/72309. Acesso em: 05 mar. 2021.

VIANNA, Cláudia Pereira. O sexo e o gênero da docência. Cadernos Pagu, n. 17-18, p. 81-103, 2002. Disponivel em: $\quad$ http://www.scielo.br/scielo.php?script=sci_arttext\&pid=S010483332002000100003\&lng=en\&nrm=iso. Acesso em: 20 mar. 2021.

Data de submissão: 07/07/2021. Data de aprovação: 02/11/2021. 